\title{
Monitoring high-ozone events in the US Intermountain West using TEMPO geostationary satellite observations
}

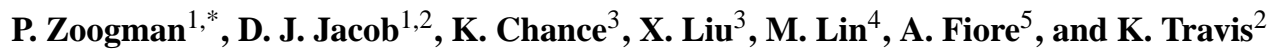 \\ ${ }^{1}$ Department of Earth and Planetary Sciences, Harvard University, Cambridge, MA, USA \\ ${ }^{2}$ School of Engineering and Applied Sciences, Harvard University, Cambridge, MA, USA \\ ${ }^{3}$ Harvard-Smithsonian Center for Astrophysics, Cambridge, MA, USA \\ ${ }^{4}$ Atmospheric and Ocean Sciences, Princeton University, Princeton, NJ, USA \\ ${ }^{5}$ Lamont-Doherty Earth Observatory, Columbia University, Palisades, NY, USA \\ * currenty at: Harvard-Smithsonian Center for Astrophysics, Cambridge, MA, USA \\ Correspondence to: P. Zoogman (pzoogman@cfa.harvard.edu)
}

Received: 23 October 2013 - Published in Atmos. Chem. Phys. Discuss.: 23 December 2013

Revised: 6 May 2014 - Accepted: 7 May 2014 - Published: 25 June 2014

\begin{abstract}
High-ozone events, approaching or exceeding the National Ambient Air Quality Standard (NAAQS), are frequently observed in the US Intermountain West in association with subsiding air from the free troposphere. Monitoring and attribution of these events is problematic because of the sparsity of the current network of surface measurements and lack of vertical information. We present an Observing System Simulation Experiment (OSSE) to evaluate the ability of the future geostationary satellite instrument Tropospheric Emissions: Monitoring of Pollution (TEMPO), scheduled for launch in 2018-2019, to monitor and attribute high-ozone events in the Intermountain West through data assimilation. TEMPO will observe ozone in the ultraviolet (UV) and visible (Vis) bands to provide sensitivity in the lower troposphere. Our OSSE uses ozone data from the GFDL AM3 chemistry-climate model (CCM) as the "true" atmosphere and samples it for April-June 2010 with the current surface network (CASTNet -Clean Air Status and Trends Networksites), a configuration designed to represent TEMPO, and a low Earth orbit (LEO) IR (infrared) satellite instrument. These synthetic data are then assimilated into the GEOSChem chemical transport model (CTM) using a Kalman filter. Error correlation length scales $(500 \mathrm{~km}$ in horizontal, $1.7 \mathrm{~km}$ in vertical) extend the range of influence of observations. We show that assimilation of surface data alone does not adequately detect high-ozone events in the Intermountain West. Assimilation of TEMPO data greatly improves the monitoring capability, with little information added from the
\end{abstract}

LEO instrument. The vertical information from TEMPO further enables the attribution of NAAQS exceedances to background ozone. This is illustrated with the case of a stratospheric intrusion.

\section{Introduction}

Harmful impacts of surface level ozone on both humans and vegetation is of increasing concern in areas formerly considered remote. The US Environmental Protection Agency (EPA) is considering lowering the current National Ambient Air Quality Standard (NAAQS) of 75 ppbv (parts per billion by volume, fourth highest maximum daily $8 \mathrm{~h}$ average per year) to a value in the range of 60-70 ppbv (EPA, 2012). Ozone concentrations in this range are frequently observed at high-elevation sites in the Western US with minimal local pollution influence (Lefohn et al., 2001). Although ozone levels have been decreasing over the Eastern US for the past two decades due to emissions controls, there has been no such decrease in the West except for California (Cooper et al., 2012). Free tropospheric ozone at 3-8 km altitude over the Western US has been increasing by 0.41 ppbv year $^{-1}$ during the past two decades (Cooper et al., 2012), which could affect background surface concentrations in the West (Zhang et al., 2008). There has been great interest in using satellite observations of ozone and related species to monitor and attribute background surface ozone (Lin et al., 2012a; Fu et al., 
2013). This capability has been limited so far by the temporal sparseness of satellite data and low sensitivity to the surface. All satellite measurements so far have been from low Earth orbit (LEO). Here we show that multispectral measurements from a configuration designed to represent the best current estimate of the NASA Tropospheric Emissions: Monitoring of Pollution (TEMPO) geostationary satellite mission over North America, scheduled for launch in 2018-2019, can provide a powerful ozone monitoring resource to complement surface sites, and can help to identify NAAQS exceedances caused by elevated background ozone.

The North American background is defined by the EPA as the surface ozone concentration that would be present over the US in the absence of North American anthropogenic emissions. It includes natural sources and intercontinental pollution, and represents a floor for the achievable benefits from domestic emissions control policies (including agreements with Canada and Mexico). The North American background is particularly high in the Intermountain West, a region extending between the Sierra Nevada/Cascades on the west and the Rocky Mountains on the east, due to high elevation and arid terrain (Zhang et al., 2011). Subsidence of high-ozone air from the free troposphere can cause surface ozone concentrations in that region to approach or exceed the NAAQS (Reid et al., 2008). This is not an issue in the Eastern US because of lower elevation, forest cover, and high moisture (Fiore et al., 2002).

Background effects on surface ozone air quality are important to diagnose, as NAAQS exceedances can be dismissed as exceptional events if shown to be not reasonably controllable by local governances (EPA, 2013). Monitoring of ozone in the Intermountain West is mostly performed at urban stations designed to observe local pollution and not background influences. There is a limited network of Clean Air Status and Trends Network (CASTNet; www.epa.gov/castnet) sites located at national parks and other remote locations, and these have been used extensively to estimate background ozone and evaluate models (Fiore et al., 2002; Zhang et al., 2011; Lin et al., 2012b; Cooper et al., 2012). Langford et al. (2009) demonstrated that transport of stratospheric air contributed to surface 1-minute average ozone concentrations in excess of $100 \mathrm{ppbv}$ in Colorado in 1999. Analysis of ozonesonde and lidar measurements by Lin et al. (2012b) indicates thirteen stratospheric intrusions in spring 2010 leading to observed maximum daily $8 \mathrm{~h}$ average (MDA8) ozone of 70-86 ppbv at surface sites. Yates et al. (2013) similarly demonstrated a stratospheric origin for a NAAQS exceedance in Wyoming in June 2012 by using a combination of 3-D modeling, aircraft observations, LEO satellite data, and geostationary weather satellites. But the current air quality observing system is very limited in its ability to (1) monitor ozone at sites prone to high background, and (2) diagnose the origin of high-ozone events at these sites.

Several chemical transport models (CTMs) and one chemistry-climate model (CCM) have been used to esti- mate the North American background including GEOSChem (Fiore et al., 2003; Zhang et al., 2011), GFDL AM3 CCM (Lin et al., 2012a, b), CMAQ (Mueller and Mallard, 2011), and CAMx (Emery et al., 2012). Values average 30$50 \mathrm{ppbv}$ in spring and summer over the Intermountain West with events exceeding 60 ppbv. There are large differences between models reflecting variable contributions from the stratosphere (Lin et al., 2012b), lightning (Kaynak et al., 2008; Zhang et al., 2011), and wildfires (Mueller and Mallard, 2011; Zhang et al., 2011; Jaffe and Wigder, 2012; Singh et al., 2012).

Geostationary satellites are a promising tool to address the limitations of the current observing system (Fishman et al., 2012; Lahoz et al., 2012). These satellites orbit the Earth with a $24 \mathrm{~h}$ period in an equatorial plane, thus continuously staring at the same scenes. Depending on the observing strategy, they may provide hourly ozone data over a continental domain, while a LEO satellite may offer at best a 1-day return time. A global constellation of geostationary satellite missions targeted at air quality is planned to launch in 20182019 including TEMPO over North America (Chance et al., 2012), Sentinel-4 over Europe (Ingmann et al., 2012), and GEMS over East Asia (Kim, 2012; Bak et al., 2013).

TEMPO will measure backscattered solar radiation in the 290-740 $\mathrm{nm}$ range, including the ultraviolet (UV) and visible Chappuis (Vis) ozone bands (Chance et al., 1997; Liu et al., 2005). Sentinel-4 and GEMS will only measure ozone in the UV. Observation in the weak Chappuis band takes advantage of the relative transparency of the atmosphere in the Vis to achieve sensitivity to near-surface ozone (Natraj et al., 2011; Selitto et al., 2012a). An Observing System Simulation Experiment (OSSE) by Zoogman et al. (2011) shows that a $\mathrm{UV}+\mathrm{Vis}$ instrument in geostationary orbit could provide useful constraints on surface ozone through data assimilation.

Here we conduct an OSSE to quantify the potential of geostationary ozone measurements from TEMPO to improve monitoring of ozone NAAQS exceedances in the Intermountain West and the role of background ozone in causing these exceedances. Our goal is to inform the TEMPO observing strategy and develop methods for exploitation of TEMPO data. OSSEs have previously informed mission planning for geostationary observations of atmospheric composition (Edwards et al., 2009; Timmermans et al., 2009; Claeyman et al., 2011; Zoogman et al., 2011, 2014; Selitto et al., 2014). An important feature of our work here is the inclusion of surface network and LEO satellite observations in the data assimilation system to properly quantify the added benefit of TEMPO observations.

Section 2 outlines the OSSE framework including a description and comparison of the simulation models used, the present and future observing systems considered, the data assimilation system, and the quantification of the error correlation length scales. Section 3 describes the OSSE results showing improved monitoring of surface ozone across the Intermountain West from TEMPO observations and improved 
detection of high-ozone events in the Intermountain West by data assimilation. Section 4 presents a case study of a stratospheric intrusion demonstrating the detection of an exceptional ozone event by TEMPO and its attribution to the North American background. Section 5 summarizes the results and discusses future research directions.

\section{Observing System Simulation Experiment (OSSE)}

OSSEs are a standard technique for assessing the information to be gained by data assimilation from adding a new instrument to an existing observing system (Lord et al., 1997). The OSSE framework involves the use of a model to generate synthetic time-varying 3-D fields of concentrations (taken as the "true" atmosphere), and the virtual sampling of this "true" atmosphere by the different instruments composing the observing system for data assimilation. This virtual sampling follows the observing schedules and error characteristics of each instrument. The virtual observations are then assimilated in a second, preferably independent, model and the results of the assimilation (with and without the new instrument) are compared to the "true" atmosphere to assess the value of the new instrument (Edwards et al., 2009).

We conduct our OSSE for April-June 2010, corresponding to the seasonal maximum in background ozone over the Intermountain West (Brodin et al., 2010). The observing system includes the CASTNet surface network, a LEO instrument, and TEMPO. The LEO and TEMPO instruments in this study represent the best current estimate of future instrument characteristics. The "true" atmosphere is provided by the GFDL AM3 CCM (Lin et al., 2012a, b). The model used for data assimilation ("forward model") is the GEOS-Chem CTM (Zhang et al., 2011); it generates a priori concentrations at successive time steps to be corrected to the "true" atmosphere by the observing system through data assimilation. The information provided by the observing system is quantified by the correction of the mismatch between the "true" state and the a priori. We describe below our OSSE framework including the simulation models (GFDL AM3 and GEOS-Chem), the observing system, and the data assimilation system.

\subsection{Simulation models}

We use for our "true" atmosphere the GFDL AM3 global chemistry-climate model with horizontal resolution of $1 / 2^{\circ} \times 5 / 8^{\circ}$ (latitude $\times$ longitude) nudged to reanalysis winds (Lin et al., 2012a, b). This CCM was successful in reproducing background ozone variability and exceptional events in the Western US during the CalNex (California Research at the Nexus of Air Quality and Climate Change) field campaign in April-June 2010 (Lin et al., 2012b). This is important because the "true" model should reproduce the characteristics of the observations relevant to the OSSE. Lin et

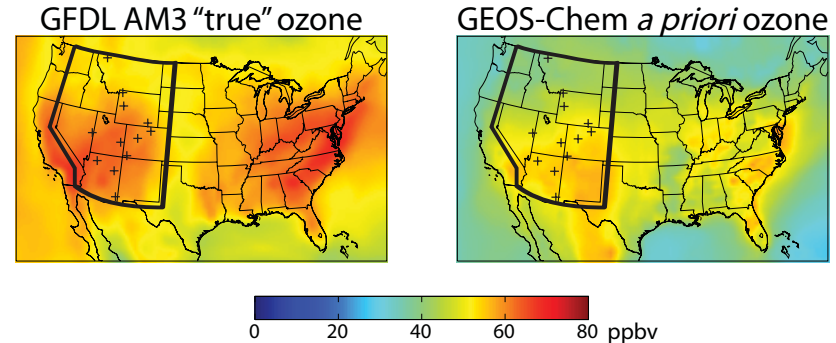

Figure 1. Mean values of the daily maximum $8 \mathrm{~h}$ average (MDA8) ozone concentrations for April-June 2010 in surface air. Left panel shows values from the GFDL AM3 CCM used as the "true" atmosphere in our OSSE. Right panel shows the a priori values from the GEOS-Chem CTM used for data assimilation. Red/blue coloring denotes relatively high/low ozone values respectively. The black lines delineate the Intermountain West and black crosses show CASTNet surface measurement sites in the region.

al. (2012a, b) used GFDL AM3 to investigate the effect of Asian transport and stratospheric intrusions on surface ozone in the Intermountain West during April-June 2010, and they quantified the ozone background through a sensitivity simulation with North American anthropogenic sources shut off. Here we use $3 \mathrm{~h}$ concentrations archived from their standard simulation to provide the global 3-D ozone fields of the "true" atmosphere.

Our forward model for data assimilation is the GEOSChem CTM (Bey et al., 2001; http://www.geos-chem.org) driven by GEOS assimilated meteorological data from the NASA Global Modeling and Assimilation Office (GMAO). The GEOS-Chem version used here (v8-02-03) was previously described by Zhang et al. (2011) in a study of background ozone influence on the Intermountain West during 2006-2008. It covers the North America domain with $1 / 2^{\circ} \times 2 / 3^{\circ}$ horizontal resolution $\left(10-60^{\circ} \mathrm{N}, 140-40^{\circ} \mathrm{W}\right)$, nested within a global domain with $2^{\circ} \times 2.5^{\circ}$ horizontal resolution. GEOS-Chem and GFDL AM3 have completely separate development heritages and use different driving meteorological fields, chemical mechanisms, and emission inventories. This independence between the two models used in the OSSE is important for a rigorous assessment (Arnold and Dey, 1986). The horizontal resolution of both models $(\sim 50 \mathrm{~km})$ is adequate for characterization of background ozone.

Figure 1 shows the maximum daily average $8 \mathrm{~h}$ (MDA8) ozone concentrations in surface air for each model, averaged over April-June 2010. GFDL AM3 has higher ozone concentrations than GEOS-Chem over the US as a whole and over the Intermountain West (bordered region) in particular. Zhang et al. (2011) previously showed that GEOS-Chem can reproduce ozone concentrations in the Intermountain West of up to $70 \mathrm{ppbv}$ with relatively little error, but cannot reproduce exceptional events of higher concentrations. GFDL AM3 has 
a high mean bias but better simulates high-ozone events than GEOS-Chem (Lin et al., 2012b).

\subsection{Observing system and synthetic observations}

Our OSSE simulates the anticipated ozone observing system over the Intermountain West during the operation of TEMPO. This will consist of surface measurements, LEO satellite measurements, and TEMPO geostationary satellite measurements. As the LEO and TEMPO instruments are still in mission planning, assumptions must be made for their final characteristics. For the LEO satellite measurements we assume a future version of the Infrared Atmospheric Sounding Interferometer (IASI) instrument, IASI3, that will be launched in 2016 on the MetOp-C satellite (Clerbaux et al., 2009). IASI retrieves ozone in the thermal infrared (TIR). We also expect to have in that time frame UV ozone observations from the TROPOspheric Monitoring Instrument (TROPOMI), scheduled for a LEO launch in 2015 (http://www.tropomi.eu). TIR and UV ozone instruments have similar vertical sensitivities (Zhang et al., 2010). TIR has the advantage of providing observations at night that will be complementary to the TEMPO mission.

CASTNet provides hourly data for 12 surface sites in the Intermountain West (Fig. 1) that are used for background monitoring (EPA, 2013). Although these sites are sparse, they are intended to be regionally representative and exhibit significant spatial correlation (Jaffe, 2011). CASTNet stations outside of the Intermountain West are not used; we assumed they do not provide useful constraints for the region but it is possible certain California sites might be exceptions. CASTNet ozone measurements have a $2 \%$ instrument error (EPA, 2010). There is additional representation error when assimilating CASTNet data into a model due to the spatial mismatch between the point where the measurement is taken and the model grid square mean to which it is compared. We find a representation error of $5 \%$ for the $\sim 50 \mathrm{~km} \times 50 \mathrm{~km}$ grid square size of GEOS-Chem, based on the model error correlation length scale (see Sect. 2.4). During nighttime the representation error could be much larger due to surface air stratification. Thus we only assimilate CASTNet data during daytime.

TEMPO and IASI-3 will both be nadir-viewing satellite instruments, with retrieval of vertical concentration profiles to be made by optimal estimation (Rodgers, 2000). If $\boldsymbol{x}_{\mathrm{p}}$ is the true profile, i.e., the vector of true concentrations in an observation column, then the retrieved profile $\boldsymbol{x}_{\mathrm{p}}^{\prime}$ is related to $\boldsymbol{x}_{\mathrm{p}}$ by the instrument averaging kernel matrix $\mathbf{A}$ which defines the sensitivity of $\boldsymbol{x}_{\mathrm{p}}^{\prime}$ to $\boldsymbol{x}_{\mathrm{p}}\left(\mathrm{A}=\partial \boldsymbol{x}_{\mathrm{p}}{ }^{\prime} / \partial \boldsymbol{x}_{\mathrm{p}}\right)$ :

$\boldsymbol{x}_{\mathrm{p}}^{\prime}=\boldsymbol{x}_{\mathrm{s}}+\mathbf{A}\left(\boldsymbol{x}_{\mathrm{p}}-\boldsymbol{x}_{\mathrm{s}}\right)+\varepsilon$,

where $\boldsymbol{\varepsilon}$ is the instrument noise vector and $\boldsymbol{x}_{\mathrm{s}}$ is an independent a priori ozone profile used to regularize the retrieval.

Figure 2 shows typical clear-sky averaging kernel matrices for UV + Vis and TIR retrievals of tropospheric ozone

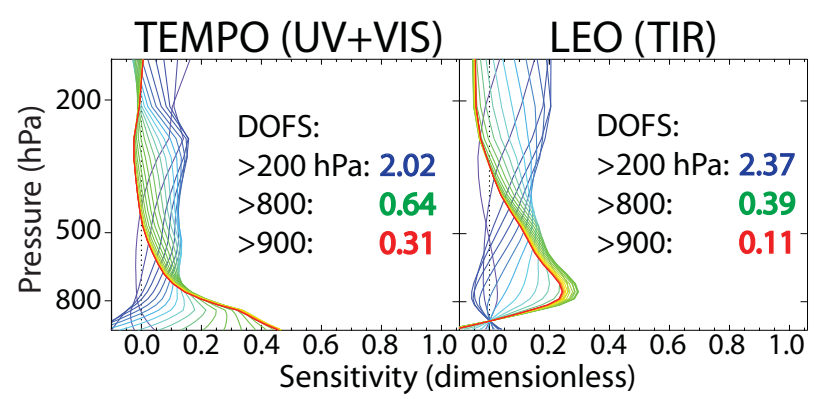

Figure 2. Normalized averaging kernel matrices assumed in this study (from Natraj et al., 2011) for clear-sky retrievals of tropospheric ozone from space in the UV + Vis (left) and the TIR (right). UV + Vis in our study corresponds to TEMPO, while TIR corresponds to a future LEO instrument flying concurrently with TEMPO. Lines are matrix rows for individual vertical levels, with the color gradient from red to blue corresponding to vertical levels ranging from surface air (red) to $200 \mathrm{hPa}$ (blue). Inset are the DOFS for the atmospheric columns below 200, 800, and $900 \mathrm{hPa}$.

taken from the Natraj et al. (2011) theoretical study. Also shown are the degrees of freedom for signal (DOFS) below given pressure levels. The DOFS are the number of independent pieces of information in the vertical provided by the retrieval, as determined from the corresponding trace of the averaging kernel matrix. The profile (index 5 from Natraj et al., 2011) used to generate these averaging kernels has moderate ozone (58 ppbv), moderate temperature contrast, and an intermediate viewing geometry, making it consistent with conditions in the Intermountain West. The assumed Vis surface albedo may be lower than the actual albedo, which would result in an underestimation of TEMPO sensitivity to nearsurface ozone. The UV + Vis spectral ranges $(290-340 \mathrm{~nm}$, $560-620 \mathrm{~nm})$ and spectral resolution $(0.4 \mathrm{~nm})$ assumed by Natraj et al. (2011) are comparable to the spectral ranges (290-490 nm, 540-740 nm) and spectral resolution (0.6 nm) planned for TEMPO. The TEMPO instrument is still under development and thus does not have its characteristics fully finalized; Natraj et al. (2011) gives the published best estimate of TEMPO ozone sensitivities. We expect TEMPO ozone sensitivities to be similar to UV + Vis sensitivities from Natraj et al. (2011). The additional near-surface information provided by the UV + Vis combination is consistent with previous work using SCIAMACHY data (Selitto et al., 2012b).

We generate synthetic geostationary observations from the GFDL AM3 "true" atmosphere by sampling daytime vertical profiles over land in the North American domain with the averaging kernel matrix given in Fig. 2. Acknowledging that the actual configuration of TEMPO is still under development, we henceforth refer to these synthetic geostationary observations as TEMPO. TEMPO observations over the ocean are not included as the planned field of regard for the mission includes very little ocean and because the clear 
ocean surface is too dark for Vis retrievals. We similarly generate synthetic LEO IASI-3 (henceforth LEO) observations over the North American domain twice a day (local noon and midnight) with the averaging kernel matrix given in Fig. 2. These TIR measurements are intended as representative of ozone observations from LEO instruments operational during the TEMPO lifetime. We omit scenes with cloud fraction $>0.3$ (as given by the GEOS meteorological data). We assume fixed averaging kernel matrices, acknowledging that in practice there is significant variability (Worden et al., 2013). Gaussian noise is added to the synthetic observations following Natraj et al. (2011) to simulate the random error associated with the spectral measurement. The noise from the TEMPO instrument (footprint of $4 \mathrm{~km} \times 8 \mathrm{~km}$ ) is reduced by the square root of the number of observations averaged over each GEOS-Chem grid square $(\sim 50 \mathrm{~km} \times 50 \mathrm{~km})$ in the data assimilation process. Since the TEMPO measurements are spatially dense we assume zero representation error during assimilation. Current IASI measurements have footprint diameters of $12-40 \mathrm{~km}$ with centers spaced $25-80 \mathrm{~km}$ apart (August et al., 2012); no reduction of the random error is applied to the LEO observations.

\subsection{Assimilation of surface and satellite measurements}

The goal of our data assimilation system is to optimize an $n$ element state vector $(\boldsymbol{x})$ of 3-D tropospheric ozone concentrations over the North American domain of GEOS-Chem, using surface and satellite observations to correct the GEOSChem simulation at successive time steps. CASTNet and TEMPO data are assimilated at discrete $3 \mathrm{~h}$ time steps, and LEO data are assimilated at $12 \mathrm{~h}$ time steps. We use a Kalman filter, as previously applied to ozone data assimilation by Khattatov et al. (2000), Parrington et al. (2008), and Zoogman et al. (2011). At each time step, we calculate an optimal estimate $\hat{\boldsymbol{x}}$ of the true ozone concentrations $\boldsymbol{x}$ as a weighted average of the model forecast $\boldsymbol{x}_{\mathrm{a}}$ (with corresponding error vector $\boldsymbol{\varepsilon}_{\mathrm{a}}$ relative to the true concentrations) and the observations $\boldsymbol{x}^{\prime}$ (with observational error $\boldsymbol{\varepsilon}^{\prime}$ and with $\boldsymbol{x}^{\prime}$ set to $\boldsymbol{x}_{\mathrm{a}}$ where there are no observations). The observational error includes both the instrument noise $\boldsymbol{\varepsilon}$ and (for surface sites) the previously defined representation error. The errors are characterized by error covariance matrices $\mathbf{S}_{\mathrm{a}}=E\left[\boldsymbol{\varepsilon}_{\mathrm{a}} \boldsymbol{\varepsilon}_{\mathrm{a}}^{T}\right]$ and $\mathbf{S}_{\boldsymbol{\varepsilon}}$ $=E\left[\boldsymbol{\varepsilon}^{\prime} \boldsymbol{\varepsilon}^{\prime T}\right]$, where $E[]$ is the expected-value operator. Assuming Gaussian error distributions for $\boldsymbol{\varepsilon}_{\mathrm{a}}$ and $\boldsymbol{\varepsilon}$ we obtain (Rodgers, 2000)

$\hat{\boldsymbol{x}}=\boldsymbol{x}_{\mathrm{a}}+\mathbf{G}\left(\boldsymbol{x}^{\prime}-\mathbf{K} \boldsymbol{x}_{\mathrm{a}}\right)$,

where $\mathbf{K}$ is the observation operator that maps the model forecast to the observations. For satellite measurements $\mathbf{K} \boldsymbol{x}_{\mathrm{a}}$ $=\boldsymbol{x}_{\mathrm{s}}+\mathbf{A}\left(\boldsymbol{x}_{\mathrm{a}}-\boldsymbol{x}_{\mathrm{s}}\right)$ (Eq. 1 with no noise term), while for surface measurements $\mathbf{K} \boldsymbol{x}_{\mathrm{a}}=\boldsymbol{x}_{\mathrm{a}}$. The gain matrix $\mathbf{G}$ is given by

$\mathbf{G}=\mathbf{S}_{\mathrm{a}} \mathbf{K}^{T}\left(\mathbf{K S}_{\mathrm{a}} \mathbf{K}^{T}+\mathbf{S}_{\boldsymbol{\varepsilon}}\right)^{-1}$ and determines the relative weight given to the observations and the model. The instrument error covariance matrix $\mathbf{S}_{\boldsymbol{\varepsilon}}$ is assumed diagonal and set to an arbitrarily large number in locations where there are no observations. For surface measurements we include the $5 \%$ representation error in quadrature with the $2 \%$ instrument error so that the corresponding error variances are additive. The optimal estimate $\hat{\boldsymbol{x}}$ has error $\hat{\boldsymbol{\varepsilon}}$ with error covariance $\hat{\mathbf{S}}=E\left[\hat{\boldsymbol{\varepsilon}} \hat{\boldsymbol{\varepsilon}}^{T}\right]$ :

$\hat{\mathbf{S}}=\left(\mathbf{I}_{n}-\mathbf{G K}\right) \mathbf{S}_{\mathrm{a}}$,

where $\mathbf{I}_{n}$ is the identity matrix of dimension $n$.

The model error covariance matrix $\mathbf{S}_{\mathrm{a}}$ expresses the error in the forward model at each assimilation time step and is given by

$\mathbf{S}_{\mathrm{a}}=\left(\begin{array}{ccc}\operatorname{var}\left(\boldsymbol{\varepsilon}_{\mathrm{a}, 1}\right) & \cdots & \operatorname{cov}\left(\boldsymbol{\varepsilon}_{\mathrm{a}, 1}, \boldsymbol{\varepsilon}_{\mathrm{a}, n}\right) \\ \vdots & \ddots & \vdots \\ \operatorname{cov}\left(\boldsymbol{\varepsilon}_{\mathrm{a}, n}, \boldsymbol{\varepsilon}_{\mathrm{a}, 1}\right) & \cdots & \operatorname{var}\left(\boldsymbol{\varepsilon}_{\mathrm{a}, n}\right)\end{array}\right)$

where $\boldsymbol{\varepsilon}_{\mathrm{a}}=\left(\boldsymbol{\varepsilon}_{\mathrm{a}, 1}, \ldots, \boldsymbol{\varepsilon}_{\mathrm{a}, n}\right)^{T}$, with $\boldsymbol{\varepsilon}_{\mathrm{a}, i}$ representing the error for GEOS-Chem grid box $i$. Following Zoogman et al. (2011), we initialize $\mathbf{S}_{\mathrm{a}}$ at the beginning of the simulation as a diagonal matrix with a priori errors of $29 \%$ (quantified by comparison of GEOS-Chem to ozonesonde measurements), and update it at each assimilation time step on the basis of the computed a posteriori error covariance matrix $\hat{\mathbf{S}}$ (Eq. 4). The diagonal terms of $\hat{\mathbf{S}}$ are transported as tracers in GEOS-Chem to the next assimilation time step and are augmented by a model error variance reflecting the timedependent divergence of the model from the true state (Zoogman et al., 2011). This yields the diagonal terms $\operatorname{var}\left(\boldsymbol{\varepsilon}_{\mathrm{a}, i}\right)$ of $\mathbf{S}_{\mathrm{a}}$ for the next assimilation time step. The off-diagonal terms (error covariances) describe the propagation of information from each observation over a spatial domain of influence. We compute $\operatorname{cov}\left(\boldsymbol{\varepsilon}_{\mathrm{a}, i}, \boldsymbol{\varepsilon}_{\mathrm{a}, j}\right)$ for each pair of grid boxes $(i, j)$ as a function of the horizontal and vertical distance between the two grid boxes using the error correlation length scales from Sect. 2.4.

In practice the dimension of the matrices used in the assimilation must be limited to make the computation tractable. This is done by solving Eq. (2) column by column and including only measurements at a horizontal distance of less than $510 \mathrm{~km}$ (the horizontal error correlation length scale, see below) in the model error covariance matrix.

\subsection{Error correlation length scales}

The spatial extent of information provided by an observation to correct the GEOS-Chem model simulation through data assimilation can be quantified by correlating the GEOSChem errors relative to in situ observations at different sites in the Intermountain West (for the horizontal scale) and ozonesonde profiles (for the vertical scale). To define a horizontal error correlation length scale we used actual 


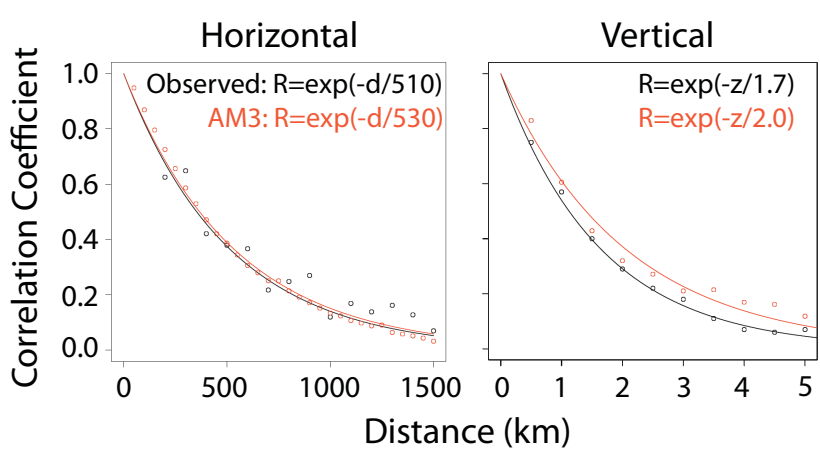

Figure 3. Error correlation length scales for the GEOS-Chem model simulation of tropospheric ozone in the US Intermountain West. The error correlations are relative to actual CASTNet and ozonesonde observations (in black) and relative to the GFDL AM3 model sampled in the Intermountain West region (in red). Statistics are computed for April-June 2010. The left panel shows the correlation coefficient $(R)$ of the model error between pairs of CASTNet sites, plotted against the distance between sites. Values are for the 12 CASTNet sites in the Intermountain West (Fig. 1). The right panel shows the correlation coefficient of the model error between pairs of vertical levels (up to $8 \mathrm{~km}$ altitude) for ozonesonde measurements from the IONS-2010 campaign in California (Cooper et al., 2011), plotted against distance between levels. Exponential fits to the data are shown inset, where $d$ and $z$ are horizontal and vertical distances in kilometers.

CASTNet surface measurements from our period of study (April-June 2010), downloaded from http://epa.gov/castnet/. We compute the time series of model error during daytime (09:00-17:00 local time) at each surface site, and from there derive the model error correlation between each pair of surface sites. Figure 3 (left) shows the correlation coefficients plotted against the distance $d$ between sites (binned every $100 \mathrm{~km})$. We find $R=\exp (-d / 510 \mathrm{~km})$. We also show the error correlation length scale calculated when comparing GEOS-Chem and GFDL AM3 (in red) sampled over the Intermountain West region. The model-model error correlation length scale is similar to the model-observation length scale, providing support for the realism of error patterns in our OSSE. We assume that the horizontal error correlation length scale is invariant with altitude.

To estimate the vertical correlation length scale we compare GEOS-Chem ozone concentrations to in situ vertical profiles from May-June 2010 ozonesondes at six locations in California (Cooper et al., 2011). Figure 3 (right) shows the correlation coefficients plotted against the vertical distance $z$ (binned every $500 \mathrm{~m}$ ) for the time series of model errors at each ozonesonde station from the surface to $8 \mathrm{~km}$ altitude. We find $R=\exp (-z / 1.7 \mathrm{~km})$. Again, the modelmodel length scale (red) is not significantly different from the model-observation length scale.

\section{TEMPO observation of high-ozone events in the Intermountain West}

We now apply our OSSE system to evaluate the benefit of TEMPO observations to monitor and attribute ozone exceedances in the Intermountain West. We compare the "true" concentrations in surface air over the Intermountain West to GEOS-Chem CTM ozone concentrations without data assimilation (a priori) and with assimilation of synthetic CASTNet, TEMPO, and IASI-3 LEO observations. We also performed an assimilation of CASTNet and TEMPO observations without a LEO instrument and found no significant difference in results. Thus the LEO instrument does not add significant information beyond TEMPO for constraining surface ozone concentrations in the Intermountain West. Its value for tracking exceptional events will be discussed in Sect. 4.

Figure 4 examines the ability of the data assimilation system to monitor daily MDA8 ozone over the Intermountain West at the $1 / 2^{\circ} \times 2 / 3^{\circ}(\sim 50 \mathrm{~km} \times 50 \mathrm{~km})$ GEOS-Chem grid resolution. The top panel shows a scatterplot of a priori GEOS-Chem MDA8 ozone concentrations in AprilJune 2010, for individual grid squares over the Intermountain West domain in Fig. 1 and individual days vs. the "true" concentrations from the GFDL AM3 model. The GEOS-Chem a priori is biased low and performs poorly in reproducing the "true" variability $\left(R^{2}=0.12\right.$, bias $\left.=-9.0 \mathrm{ppbv}\right)$. Assimilation of synthetic CASTNet surface measurements reduces the low bias from 9.0 to $2.8 \mathrm{ppbv}$, but still does not capture much of the variability $\left(R^{2}=0.34\right)$. Adding the synthetic TEMPO geostationary observations eliminates the low bias and captures over half of the variability $\left(R^{2}=0.58\right)$.

The ability of TEMPO observations to capture high-ozone events is of particular interest. Figure 5 shows a map of the number of days in April-June 2010 with MDA8 ozone in excess of $70 \mathrm{ppbv}$ for individual GEOS-Chem grid squares in the Intermountain West. Values are shown for the "true" atmosphere, the GEOS-Chem a priori without data assimilation, and the data assimilation results including only the CASTNet observations and with the addition of TEMPO observations. The "truth" shows an average of 5.7 high-ozone events per grid square in the Intermountain West over AprilJune 2010. The a priori model has only 0.8 event days per grid square and the spatial pattern is very different (spatial correlation $R^{2}=0.09$ for the ensemble of Intermountain West grid squares). Assimilation of surface measurements improves both the average number of high-ozone events (3.6 event days) and the spatial pattern $\left(R^{2}=0.62\right)$. The inability to fully correct the bias is due in part to the large impact of free tropospheric air in driving high-ozone events, and in part to the limited coverage from the sparse surface network. Adding TEMPO satellite observations almost fully corrects the bias (mean of 5.4 event days) and captures most of the spatial distribution of high-ozone events $\left(R^{2}=0.82\right)$. 


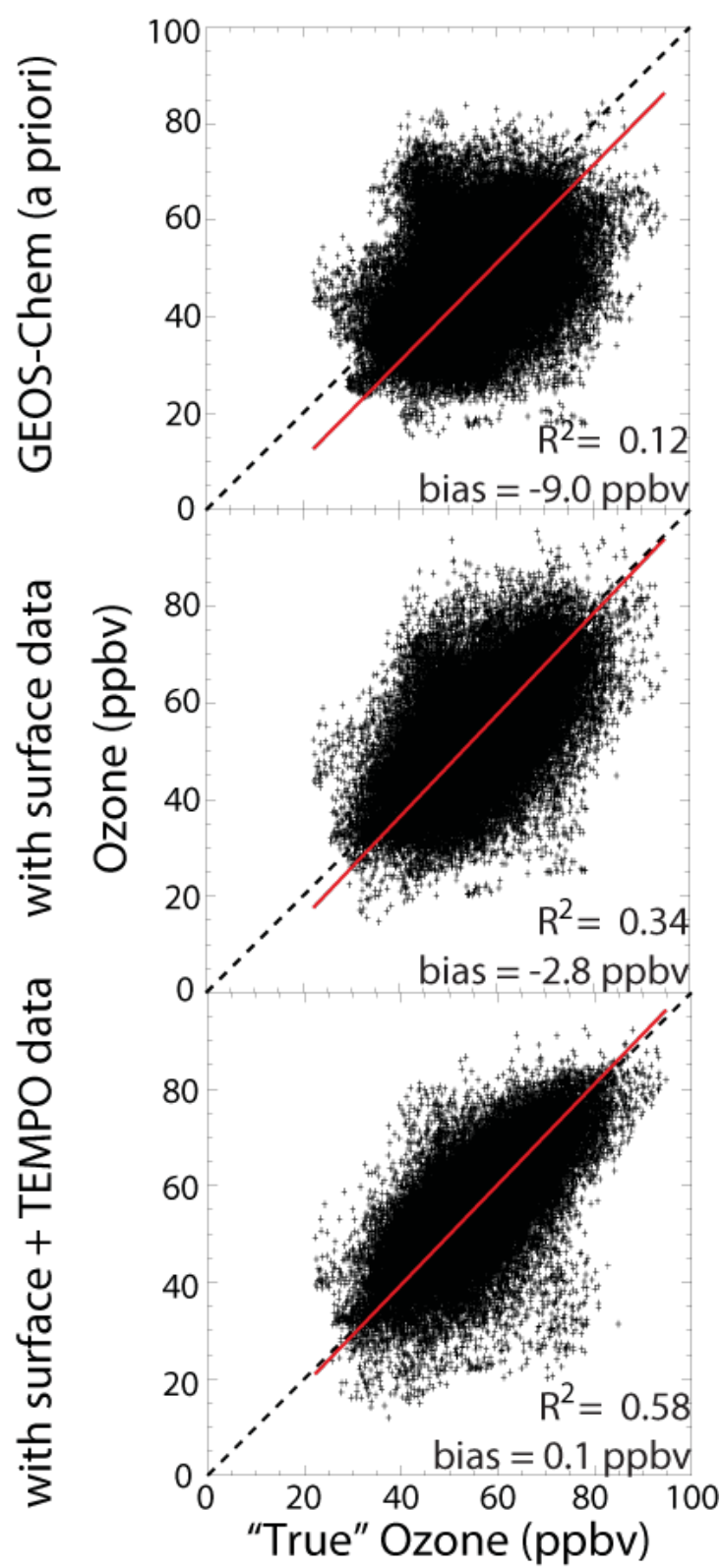

Figure 4. Improved monitoring of surface ozone across the Intermountain West from assimilation of synthetic CASTNet (surface) and TEMPO (geostationary satellite) observations. The figure shows scatterplots of simulated (GEOS-Chem) vs. "truth" (GFDL AM3) daily maximum $8 \mathrm{~h}$ (MDA8) surface ozone for April-June 2010 for all $1 / 2^{\circ} \times 2 / 3^{\circ}$ grid squares in the region (Fig. 1) and for individual days. Results are for GEOS-Chem without data assimilation (top), with assimilation of CASTnet synthetic surface data (middle), and with additional assimilation of TEMPO and LEO synthetic satellite data (bottom). Comparison statistics are inset. Also shown are the reduced-major-axis (RMA) regression line and the $1: 1$ line.
Number of days with MDA8 ozone $>70$ ppbv

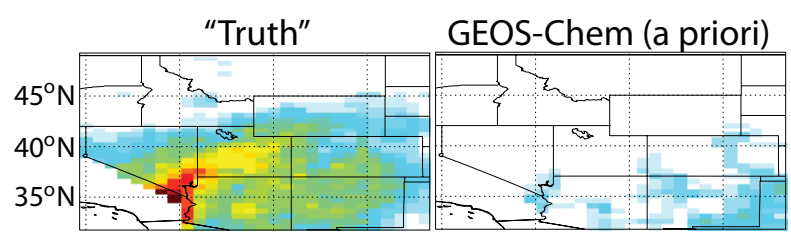

with surface data with surface + TEMPO data

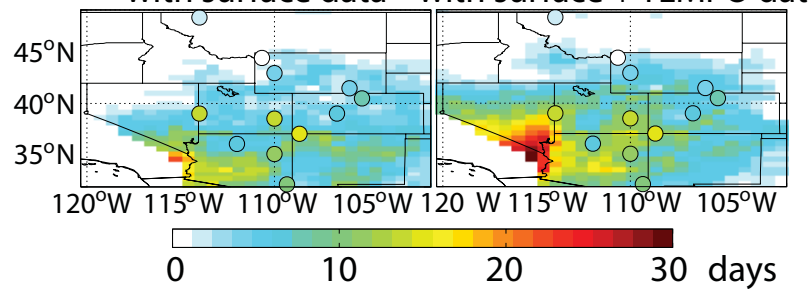

Figure 5. Improved detection of high-ozone events in the Intermountain West by data assimilation. The figure shows the number of events (daily maximum $8 \mathrm{~h}$ ozone $>70 \mathrm{ppbv}$ ) in April-June 2010 on the GEOS-Chem grid. The "truth" defined by the GFDL AM3 model (top left panel) is compared to GEOS-Chem simulations without data assimilation (top right), with assimilation of synthetic CASTNet surface data (bottom left), and with additional assimilation of synthetic TEMPO and LEO satellite data (bottom right). Locations of CASTNet surface sites used for assimilation with their "true" values are overlain in the bottom panels.

\section{Attribution of exceptional events using TEMPO observations}

TEMPO will provide continuous daytime observation in the free troposphere as well as in the boundary layer, with separation between the two (Fig. 2). Thus it could be particularly powerful in quantifying free tropospheric background contributions to NAAQS exceedances. This would assist in the designation of exceptional events where an exceedance of the NAAQS is considered to be outside of local control.

We examine a case study of a stratospheric intrusion on 13 June in the GFDL AM3 model taken as the "truth". Figure 6 shows a time series for June 2010 of MDA8 ozone concentrations at a location in northern New Mexico $\left(107^{\circ} \mathrm{W}, 36^{\circ} \mathrm{N}\right)$. We choose this event as it was diagnosed by ozonesonde observations and meteorological tracers as a deep stratospheric intrusion event (Lin et al., 2012a). Actual observations at nearby CASTNet locations indicate ozone in excess of $75 \mathrm{ppbv}$ during this modeled intrusion.

Evidence of free tropospheric origin for the 13 June event is critical to achieving an "exceptional event" designation. Figure 7 (top left) shows a longitude-altitude cross section of ozone concentrations in the GFDL AM3 model taken as the "truth". The stratospheric intrusion is manifest at 103 $109^{\circ} \mathrm{W}$. The a priori GEOS-Chem model (top right) also shows a stratospheric ozone enhancement extending to the surface but of much smaller magnitude. Assimilation of surface measurements (not shown) makes little correction in the 


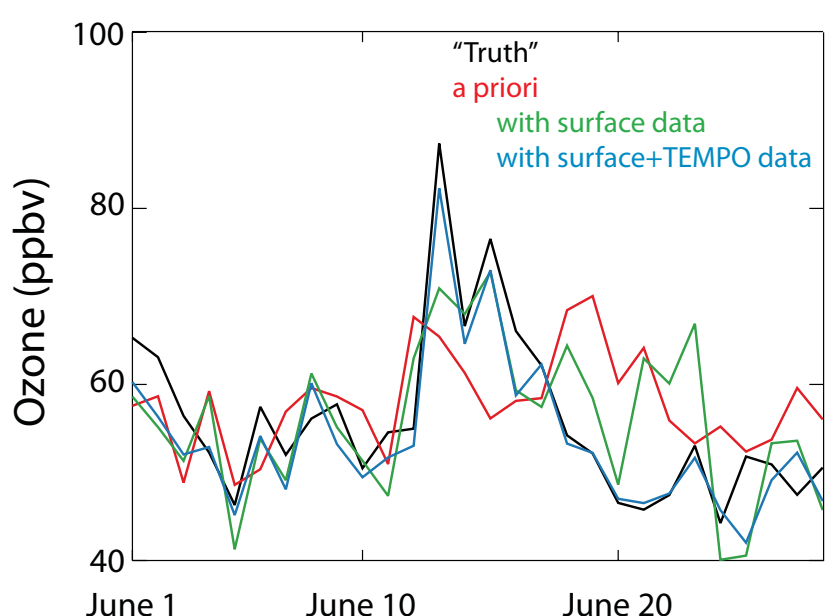

Figure 6. Detection of an exceptional ozone event by TEMPO. The figure shows the June 2010 time series of daily maximum $8 \mathrm{~h}$ (MDA8) ozone concentrations at a location in northern New Mexico $\left(107^{\circ} \mathrm{W}, 36^{\circ} \mathrm{N}\right)$ featuring a major stratospheric intrusion on 13 June in the GFDL AM3 model taken as the "truth" (black line). The ability to capture this event is examined for the GEOS-Chem model without data assimilation (a priori, red line) and with assimilation of surface measurements only (green line) and satellite measurements added (blue line).

free troposphere. Synthetic satellite measurement imagery from TEMPO without assimilation (bottom left) shows elevated values in the free troposphere but does not properly represent surface gradients due to instrument smoothing. Assimilating TEMPO observations into the GEOS-Chem CTM together with LEO measurements (bottom right) captures the magnitude and spatial structure of the stratospheric intrusion, and this would make a strong case for diagnosis of an exceptional event. We see here that the use of data assimilation efficiently enhances the information from TEMPO to constrain surface air concentrations. Information from the LEO instrument does not add significantly in this case to observations from TEMPO, although it does correct ozone fields over the ocean where TEMPO does not observe in this OSSE. The LEO instrument will thus be valuable for tracking transpacific transport of ozone plumes even when TEMPO is operational.

\section{Summary}

We demonstrated the potential of future TEMPO UV + Vis geostationary observations to monitor ozone exceedances in the Intermountain West and identify those exceedances caused by the North American background. Our goal was to inform the TEMPO observing strategy and develop methods for exploitation of its data. To accomplish this we performed an OSSE for assimilation of synthetic TEMPO data designed to best represent future observations based on current esti-

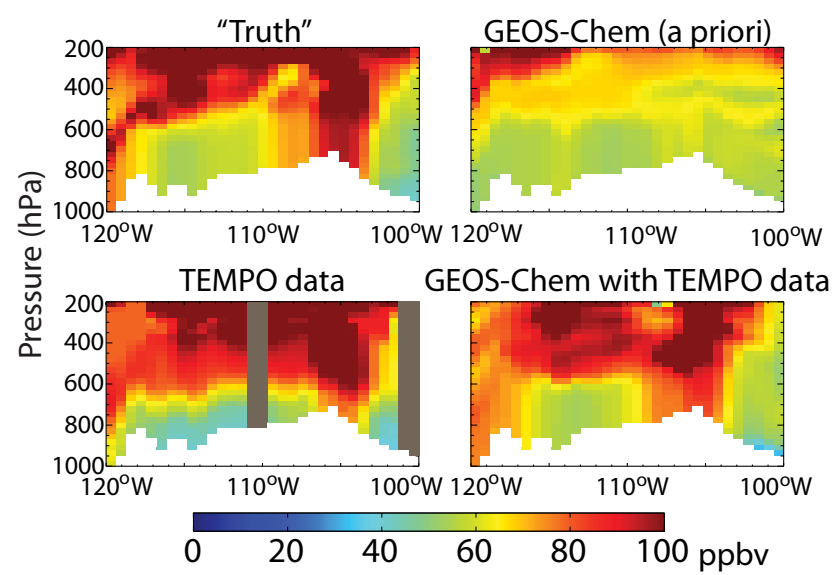

Figure 7. Longitude-altitude cross section of ozone concentrations ( $36^{\circ} \mathrm{N}, 21: 00$, mountain time, on 13 June 2010 ) associated with the stratospheric intrusion of Fig. 6. The "true" state from the GFDL AM3 model (top left) is compared to the GEOS-Chem model without data assimilation (top right) and with assimilation of surface and satellite data (bottom right). The bottom left panel shows synthetic TEMPO observations of the "true" state (gray regions indicate cloudy scenes) without data assimilation. Orange and red values indicate ozone levels that would lead to exceedances of the current NAAQS of 75 ppbv. Local topography is shown in white.

mates of TEMPO instrument characteristics. We used two global 3-D ozone models with $\sim 50 \mathrm{~km}$ horizontal resolution, one as the "true" atmosphere and one as the forward model for data assimilation. We also included in our OSSE surface measurements from the current CASTNet monitoring network sites in the Intermountain West (12 sites) and satellite measurements from a TIR LEO instrument projected to be in orbit concurrently with TEMPO.

An important factor in data assimilation is the scales over which observed information can be propagated with the forward model. We quantified this using model error correlation length scales for the Intermountain West based on actual CASTNet and ozonesonde data. We find length scales of 500 (horizontal) and $1.7 \mathrm{~km}$ (vertical). These are in close agreement with error correlation length scales between the two models used in our OSSE.

We find that the CASTNet surface observations are too sparse to adequately monitor high-ozone events in the Intermountain West even after data assimilation. We show that the TEMPO geostationary observations will provide a greatly improved observing system for monitoring such events, eliminating the a priori model bias, capturing $58 \%$ of surface MDA8 ozone variability, and capturing $82 \%$ of the distribution of high-ozone days. In addition, because of the information they provide on the vertical distribution of ozone, they can effectively diagnose NAAQS exceedances caused by background ozone. Our evidence indicates that a LEO satellite instrument flying concurrently with TEMPO provides no significant added value for monitoring the ozone 
background over the US but could be useful for tracking transpacific plumes.

The use of invariant averaging kernel matrices is a limitation of this study. Preparation for TEMPO must include improved constraints on physical parameters, such as surface albedo, that can vary greatly over the North American domain and that affect the sensitivity of UV + Vis retrievals of near-surface ozone. Also, if the differences between the two models used in our OSSE are larger than future errors in modeled ozone, this study may overestimate the information TEMPO will provide. However, our OSSE demonstrates the large relative improvement of information provided by TEMPO over the current observing system.

Use of the complete observing system described here (surface, geostationary, and LEO) will provide a powerful tool for future air quality policy. Planning is underway to combine this system with regional air quality models to supply the public with near-real-time pollution reports and forecasts. These reports and forecasts would be much the same as currently available weather information, also provided in large part from geostationary satellite observations.

Acknowledgements. This work was supported by the NASA Earth Science Division and by a NASA Earth and Space Science Fellowship to Peter Zoogman.

Edited by: W. Lahoz

\section{References}

Arnold, C. and Dey, C.: Observing-systems simulation experiments - past, present, and future, B. Am. Meteorol. Soc., 67, 687-695, 1986.

August, T., Klaes, D., Schluessel, P., Hultberg, T., Crapeau, M., Arriaga, A., O'Carroll, A., Coppens, D., Munro, R., and Calbet, X.: IASI on metop-A: Operational level 2 retrievals after five years in orbit, J. Quant. Spectrosc. Ra., 113, 1340-1371, 2012.

Bak, J., Kim, J. H., Liu, X., Chance, K., and Kim, J.: Evaluation of ozone profile and tropospheric ozone retrievals from GEMS and OMI spectra, Atmos. Meas. Tech., 6, 239-249, doi:10.5194/amt6-239-2013, 2013.

Bey, I., Jacob, D., Yantosca, R., Logan, J., Field, B., Fiore, A., Li, Q., Liu, H., Mickley, L., and Schultz, M.: Global modeling of tropospheric chemistry with assimilated meteorology: Model description and evaluation, J. Geophys. Res.-Atmos., 106, 2307323095, 2001.

Brodin, M., Helmig, D., and Oltmans, S.: Seasonal ozone behavior along an elevation gradient in the colorado front range mountains, Atmos. Environ., 44, 5305-5315, 2010.

Chance, K., Burrows, J., Perner, D., and Schneider, W.: Satellite measurements of atmospheric ozone profiles, including tropospheric ozone, from ultraviolet/visible measurements in the nadir geometry: A potential method to retrieve tropospheric ozone, J. Quant. Spectrosc. Ra., 57, 467-476, 1997.
Chance, K., Lui, X., Suleiman, R. M., Flittner, D. E., and Janz, S. J.: Tropspheric Emissions: Monitoring of Pollution (TEMPO), Abstract A31B-0020 presented at the 2012 AGU Fall Meeting, 2012.

Claeyman, M., Attié, J.-L., Peuch, V.-H., El Amraoui, L., Lahoz, W. A., Josse, B., Joly, M., Barré, J., Ricaud, P., Massart, S., Piacentini, A., von Clarmann, T., Höpfner, M., Orphal, J., Flaud, J.M., and Edwards, D. P.: A thermal infrared instrument onboard a geostationary platform for $\mathrm{CO}$ and $\mathrm{O}_{3}$ measurements in the lowermost troposphere: Observing System Simulation Experiments (OSSE), Atmos. Meas. Tech., 4, 1637-1661, doi:10.5194/amt-41637-2011, 2011.

Clerbaux, C., Boynard, A., Clarisse, L., George, M., Hadji-Lazaro, J., Herbin, H., Hurtmans, D., Pommier, M., Razavi, A., Turquety, S., Wespes, C., and Coheur, P.-F.: Monitoring of atmospheric composition using the thermal infrared IASI/MetOp sounder, Atmos. Chem. Phys., 9, 6041-6054, doi:10.5194/acp-9-6041-2009, 2009.

Cooper, O. R., Oltmans, S. J., Johnson, B. J., Brioude, J., Angevine, W., Trainer, M., Parrish, D. D., Ryerson, T. R., Pollack, I., Cullis, P. D., Ives, M. A., Tarasick, D. W., Al-Saadi, J., and Stajner, I.: Measurement of western US baseline ozone from the surface to the tropopause and assessment of downwind impact regions, J. Geophys. Res.-Atmos., 116, D00V03, doi:10.1029/2011JD016095, 2011.

Cooper, O. R., Gao, R., Tarasick, D., Leblanc, T., and Sweeney, C.: Long-term ozone trends at rural ozone monitoring sites across the United States, 1990-2010, J. Geophys. Res.-Atmos., 117, D22307, doi:10.1029/2012JD018261, 2012.

Edwards, D. P., Arellano Jr., A. F., and Deeter, M. N.: A satellite observation system simulation experiment for carbon monoxide in the lowermost troposphere, J. Geophys. Res.-Atmos., 114, D14304, doi:10.1029/2008JD011375, 2009.

Emery, C., Jung, J., Downey, N., Johnson, J., Jimenez, M., Yarvvood, G., and Morris, R.: Regional and global modeling estimates of policy relevant background ozone over the United States, Atmos. Environ., 47, 206-217, 2012.

Fiore, A., Jacob, D., Bey, I., Yantosca, R., Field, B., Fusco, A., and Wilkinson, J.: Background ozone over the United States in summer: Origin, trend, and contribution to pollution episodes, J. Geophys. Res.-Atmos., 107, 4275, doi:10.1029/2001JD000982, 2002.

Fiore, A., Jacob, D., Liu, H., Yantosca, R., Fairlie, T., and Li, Q.: Variability in surface ozone background over the United States: Implications for air quality policy, J. Geophys. Res.-Atmos., 108, 4787, doi:10.1029/2008JD010816, 2003.

Fishman, J., Iraci, L. T., Al-Saadi, J., Chance, K., Chavez, F., Chin, M., Coble, P., Davis, C., DiGiacomo, P. M., Edwards, D., Eldering, A., Goes, J., Herman, J., Hu, C., Jacob, D. J., Jordan, C., Kawa, S. R., Key, R., Liu, X., Lohrenz, S., Mannino, A., Natraj, V., Neil, D., Neu, J., Newchurch, M., Pickering, K., Salisbury, J., Sosik, H., Subramaniam, A., Tzortziou, M., Wang, J., and Wang, M.: The united states' next generation of atmospheric composition and coastal ecosystem measurements NASA's geostationary coastal and air pollution events (GEO-CAPE) mission, B. Am. Meteorol. Soc., 93, 1547-1566, 2012. 
Fu, D., Worden, J. R., Liu, X., Kulawik, S. S., Bowman, K. W., and Natraj, V.: Characterization of ozone profiles derived from Aura TES and OMI radiances, Atmos. Chem. Phys., 13, 3445-3462, doi:10.5194/acp-13-3445-2013, 2013.

Ingmann, P., Veihelmann, B., Langen, J., Lamarre, D., Stark, H., and Courreges-Lacoste, G. B.: Requirements for the GMES atmosphere service and ESA's implementation concept: Sentinels4/-5 and-5p, Remote Sens. Environ., 120, 58-69, 2012.

Jaffe, D.: Relationship between surface and free tropospheric ozone in the western U. S., Environ. Sci. Technol., 45, 432-438, 2011.

Jaffe, D. A. and Wigder, N. L.: Ozone production from wildfires: A critical review, Atmos. Environ., 51, 1-10, 2012.

Kaynak, B., Hu, Y., Martin, R. V., Russell, A. G., Choi, Y., and Wang, Y.: The effect of lightning $\mathrm{NO}_{\mathrm{x}}$ production on surface ozone in the continental United States, Atmos. Chem. Phys., 8, 5151-5159, doi:10.5194/acp-8-5151-2008, 2008.

Khattatov, B., Lamarque, J., Lyjak, L., Menard, R., Levelt, P., Tie, X., Brasseur, G., and Gille, J.: Assimilation of satellite observations of long-lived chemical species in global chemistry transport models, J. Geophys. Res.-Atmos., 105, 29135-29144, 2000.

Kim, J.: GEMS (Geostationary Enviroment Monitoring Spectrometer) onboard the GeoKOMPSAT to monitor air quality in high temporal and spatial resolution over Asia- Pacific region, Abstract EGU2012-4051 presented at the 2012 EGU General Assembly, 2012.

Lahoz, W. A., Peuch, V.-H., Orphal, J., Attie, J.-L., Chance, K., Liu, X., Edwards, D., Elbern, H., Flaud, J.-M., Claeyman, M., and El Amraoui, L.: Monitoring air quality from space: the case for the geostationary platform, B. Am. Meteorol. Soc., 11, 221-233, 2012.

Langford, A. O., Aikin, K. C., Eubank, C. S., and Williams, E. J.: Stratospheric contribution to high surface ozone in Colorado during springtime, Geophys. Res. Lett., 36, L12801, doi:10.1029/2009GL038367, 2009.

Lefohn, A., Oltmans, S., Dann, T., and Singh, H.: Present-day variability of background ozone in the lower troposphere, J. Geophys. Res.-Atmos., 106, 9945-9958, 2001.

Lin, M., Fiore, A. M., Cooper, O. R., Horowitz, L. W., Langford, A. O., Levy, Hiram, II, Johnson, B. J., Naik, V., Oltmans, S. J., and Senff, C. J.: Springtime high surface ozone events over the western United States: Quantifying the role of stratospheric intrusions, J. Geophys. Res.-Atmos., 117, D00V22, doi:10.1029/2012JD018151, 2012a.

Lin, M., Fiore, A. M., Horowitz, L. W., Cooper, O. R., Naik, V., Holloway, J., Johnson, B. J., Middlebrook, A. M., Oltmans, S. J., Pollack, I. B., Ryerson, T. B., Warner, J. X., Wiedinmyer, C., Wilson, J., and Wyman, B.: Transport of asian ozone pollution into surface air over the western United States in spring, J. Geophys. Res.-Atmos., 117, D00V07, doi:10.1029/2011JD016961, 2012b.

Liu, X., Sioris, C., Chance, K., Kurosu, T., Newchurch, M., Martin, R., and Palmer, P.: Mapping tropospheric ozone profiles from an airborne ultraviolet-visible spectrometer, Appl. Opt., 44, 33123319, 2005.

Lord, S. J., Kalnay, E., Daley, R., Emmitt, G. D., and Atlas, R.: Using OSSEs in the design of future $g$ eneration integrated observing systems. Preprints, 1st Symposium on Integrated Observing Systems, Long Beach, CA, AMS, 45-47, 1997.
Mueller, S. F. and Mallard, J. W.: Contributions of natural emissions to ozone and PM2.5 as simulated by the community multiscale air quality (CMAQ) model, Environ. Sci. Technol., 45, 48174823, 2011.

Natraj, V., Liu, X., Kulawik, S., Chance, K., Chatfield, R., Edwards, D. P., Eldering, A., Francis, G., Kurosu, T., Pickering, K., Spurr, R., and Worden, H.: Multi-spectral sensitivity studies for the retrieval of tropospheric and lowermost tropospheric ozone from simulated clear-sky GEO-CAPE measurements, Atmos. Environ., 45, 7151-7165, 2011.

Parrington, M., Jones, D. B. A., Bowman, K. W., Horowitz, L. W., Thompson, A. M., Tarasick, D. W., and Witte, J. C.: Estimating the summertime tropospheric ozone distribution over North America through assimilation of observations from the tropospheric emission spectrometer, J. Geophys. Res.-Atmos., 113, D18307, doi:10.1029/2007JD009341, 2008.

Reid, N., Yap, D., and Bloxam, R.: The potential role of background ozone on current and emerging air issues: An overview, Air Qual. Atmos. Health, 1, 19-29, 2008.

Rodgers, C. D.: Inverse Methods for Atmospheric Sounding, World Scientific, River Edge, New Jersey, 2000.

Selitto, P., Del Frate, F., Solimini, D., and Casadio, S.: Tropospheric ozone column retrieval from ESA-Envisat SCIAMACHY nadir UV/VIS radiance measurements by means of a neural network algorithm, IEEE Trans. Geosci. Remote Sens., 50, 998-1011, 2012a.

Selitto, P., Di Noia, A., Del Frate, F., Burini, A., Casadio, S., and Solimini, D.: On the role of visible radiation in ozone profile retrieval from nadir UV/VIS satellite measurements: An experiment with neural network algorithms inverting SCIAMACHY data, J. Quant. Spectrosc. Ra., 113, 1429-1436, 2012 b.

Selitto, P., Dufour, G., Eremenko, M., Cuesta, J., Forêt, G., Gaubert, B., Beekmann, M., Peuch, V.-H., and Flaud, J.-M.: Monitoring the lowermost tropospheric ozone with thermal infrared observations from a geostationary platform: performance analyses for a future dedicated instrument, Atmos. Meas. Tech., 7, 391-407, doi:10.5194/amt-7-391-2014, 2014.

Singh, H. B., Cai, C., Kaduwela, A., Weinheimer, A., and Wisthaler, A.: Interactions of fire emissions and urban pollution over California: Ozone formation and air quality simulations, Atmos. Environ., 56, 45-51, 2012.

Timmermans, R. M. A., Segers, A. J., Builtjes, P., Vautard, R., Siddans, R., Elbern, H., Tjemkes, S., and Schaap, M.: The added value of a proposed satellite imager for ground level particulate matter analyses and forecasts, IEEE J. Sel. Top. Appl., 2, 271283, 2009.

United States Environmental Protection Agency: Clean air status and trends network second quarter 2010 quality assurance report, 2010.

United States Environmental Protection Agency: Welfare Risk and Exposure Assessment for Ozone, 2012.

United States Environmental Protection Agency: Interim Guidance to Implement Requirements for the Treatment of Air Quality Monitoring Data Influenced by Exceptional Events, 2013. 
Worden, H. M., Deeter, M. N., Frankenberg, C., George, M., Nichitiu, F., Worden, J., Aben, I., Bowman, K. W., Clerbaux, C., Coheur, P. F., de Laat, A. T. J., Detweiler, R., Drummond, J. R., Edwards, D. P., Gille, J. C., Hurtmans, D., Luo, M., MartínezAlonso, S., Massie, S., Pfister, G., and Warner, J. X.: Decadal record of satellite carbon monoxide observations, Atmos. Chem. Phys., 13, 837-850, doi:10.5194/acp-13-837-2013, 2013.

Yates, E. L., Iraci, L. T., Roby, M. C., Pierce, R. B., Johnson, M. S., Reddy, P. J., Tadic, J. M., Loewenstein, M., and Gore, W.: Airborne observations and modeling of springtime stratosphereto-troposphere transport over California, Atmos. Chem. Phys., 13, 12481-12494, doi:10.5194/acp-13-12481-2013, 2013.

Zhang, L., Jacob, D. J., Boersma, K. F., Jaffe, D. A., Olson, J. R., Bowman, K. W., Worden, J. R., Thompson, A. M., Avery, M. A., Cohen, R. C., Dibb, J. E., Flock, F. M., Fuelberg, H. E., Huey, L. G., McMillan, W. W., Singh, H. B., and Weinheimer, A. J.: Transpacific transport of ozone pollution and the effect of recent Asian emission increases on air quality in North America: an integrated analysis using satellite, aircraft, ozonesonde, and surface observations, Atmos. Chem. Phys., 8, 6117-6136, doi:10.5194/acp-8-6117-2008, 2008.
Zhang, L., Jacob, D. J., Liu, X., Logan, J. A., Chance, K., Eldering, A., and Bojkov, B. R.: Intercomparison methods for satellite measurements of atmospheric composition: application to tropospheric ozone from TES and OMI, Atmos. Chem. Phys., 10, 4725-4739, doi:10.5194/acp-10-4725-2010, 2010.

Zhang, L., Jacob, D. J., Downey, N. V., Wood, D. A., Blewitt, D., Carouge, C. C., van Donkelaar, A., Jones, D. B. A., Murray, L. T., and Wang, Y.: Improved estimate of the policy- relevant background ozone in the United States using the GEOS-chem global model with $1 / 2$ degrees $x$ 2/3 degrees horizontal resolution over North America, Atmos. Environ., 45, 6769-6776, 2011.

Zoogman, P., Jacob, D. J., Chance, K., Zhang, L., Le Sager, P., Fiore, A. M., Eldering, A., Liu, X., Natraj, V., and Kulawik, S. S.: Ozone air quality measurement requirements for a geostationary satellite mission, Atmos. Environ., 45, 7143-7150, 2011.

Zoogman, P., Jacob, D. J., Chance, K., Worden, H. M., Edwards, D. P., and Zhang, L.: Improved monitoring of surface ozone air quality by joint assimilation of geostationary satellite observations of ozone and CO, Atmos. Environ., 84, 254-261, 2014. 